\title{
ОСОБЕННОСТИ МЕЖЛИЧНОСТНЫХ ОТНОШЕНИЙ ПОДРОСТКОВ С РАЗЛИЧНЫМ СОЦИОМЕТРИЧЕСКИМ СТАТУСОМ
}

\section{FEATURES OF INTERPERSONAL RELATIONSHIPS AMONG ADOLESCENTS WITH DIFFERENT SOCIOMETRIC STATUS}

\section{S. Khairova}

Summary: The article discusses individual psychological factors that ensure the effectiveness of interpersonal communication of adolescents in the space of the educational environment. Among the key components of such communication are perceptions of oneself, perceptions of others, perceptions of acceptable and unacceptable ways to resolve problem situations, as well as internal and external resources to solve them. In addition, the role of communicative skills and skills for building effective relationships is discussed. The results of an empirical analysis of the relationship of communicative skills with the level of integration of a teenager into the system of social relations in the space of the educational environment are discussed. The results of an empirical analysis of the relationship of communicative skills with the level of integration of a teenager into the system of social relations in the space of the educational environment are discussed.

Keywords: group relations, sociometric status, communication skills, selforganization, psychological well-being.
$\mathrm{O}$ бсуждение психолого-педагогических условий всестороннего и полноценного развития подростка в пространстве образовательной среды невозможно без обсуждения межличностных отношений с членами школьной группы как одного из факторов этого развития.

По мнению Мясищева В.Н. отношения личности выступают с одной стороны показателем уровня сформированности личности, ее системы ценностей, потребностей и мотивов, с другой - отражают степень интегрированности или адаптированности к той среде, в которой она находится, отражая одновременно ресурсы и возможности среды, которые использует субъект для проявления и разворачивания своей индивидуальности.

Особую актуальность межличностные отношения приобретают в подростковом возрасте. Они становятся платформой, где разворачиваются многие процессы личностного и социального созревания подростка. Благополучие в системе групповых отношений во многом определяет благополучие психического и социального развития подростка. В свою очередь, положение под-
Хаирова Селиме Изетовна

К.nсх.н., доцент, ГБОУ ВО РК «Крымский инженерно-педагогический университет» имени Февзи Якубова, Симферополь Selime_khairova@mail.ru

Аннотация: В статье обсуждаются индивидуально-психологические факторы, обеспечивающие эффективность межличностной коммуникации подростков в пространстве образовательной среды. Среди ключевых компонентов такой коммуникации рассматриваются представления о себе, представления о других, представления о допустимых и недопустимых способах разрешения проблемных ситуаций, а также о внутренних и внешних ресурсах для их решения. Обсуждается роль коммуникативных навыков и умений для построения эффективных отношений. Обсуждаются результаты эмпирического анализа взаимосвязи коммуникативных навыков с уровнем интегрированности подростка в систему социальных отношений в пространстве образовательной среды.

Ключевые слова: групповые отношения, социометрический статус, коммуникативные навыки, самоорганизация, психологическое благополучие.

ростка в иерархии групповых отношений может выступать индикатором уровня развитости навыков и умений, необходимых для эффективного построения взаимодействия с другими людьми. Как показывает практика, если эти навыки не получили должного развития, подростку оказывается очень сложно установить гармоничные отношения со своим окружением, возникает состояние внутренней дисгармонии и дезадаптированности, что отражается, в числе прочего, и на его положении в групповой иерархии.

Исходя из сказанного в качестве объекта исследования были определены межличностные отношения подростков с различным социометрическим статусом.

Цель работы заключается в том, чтобы проследить как взаимосвязаны социальные и коммуникативные навыки подростка с его положением в социальной структуре класса и определить основные направления психологической поддержки процесса групповой социализации.

Предметом обсуждения в данной статье являются результаты эмпирического исследования особенностей 
построения межличностных отношений у подростков с различным социометрическим статусом.

Проведем краткий экскурс в теорию обсуждаемого вопроса. Проблемам подросткового развития посвятили свои труды множество отечественных и зарубежных. В рамках этих исследований особое внимание уделялось проблеме отношения, обусловливающего не только личностное развитие подростка, но и качественную ассимиляцию им социального опыта (В.Н. Мясищев, А.Г. Асмолов, М.К. Павлова, А.А. Кроник, Е.А. Кроник, Б.С. Братусь, А.А. Петровский, А. Бандура, А. Айхорн, Э. Берн, А. Маслоу, М. Кле и др.) $[2,6,8]$. Как показано в работах этих авторов, многоуровневая система отношений предполагает развитие функционально-ролевых, эмоционально-оценочных, смысловых структур личности, выступающих ключевыми факторами социогенеза. Устойчивое рассогласование отношений приводит к искажённому восприятию социального опыта, формированию негативных личностных образований и в конечном итоге - к дезадаптации личности в системе межличностных коммуникации [1, 2, 3].

Значимость межличностной коммуникации для целостного гармоничного развития личности подростка раскрывали в свои работах Л.С. Выготский, Л.Н. Леонтьев, Д.Б. Эльконин, Л.И. Божович, В.В. Столин, и др. Как писала Л.И. Божович центр жизни подростка переносится из учебной деятельности в общение. Здесь происходят самые важные процессы личностного созревания, становление социального Я, освоения моральных норм и ценностей, осмысления перспектив. Если в школе подростку не удается найти удовлетворяющей его системы общения он «уходит» из школы в переносном, а иногда и в прямом смысле слова [3, 9].

Общение - это сложный процесс, навыки которого ребенок осваивает с самого рождения. Их недостаточное развитие иногда является основной причиной, по которой подросток не может интегрироваться в систему отношений в классе. Сегодня этот процесс осложняется еще и тем, что стремительная цифровизация общества с одной стороны делает жизнь подростка более насыщенной событиями, с другой - меняет условия и характер общения. На страницах родительских интернет-форумов регулярно поднимаются вопросы о том, как заставить подростков общаться с другими детьми в очном формате. Среди подростковых проблем родители и педагоги указывают отчуждение, нежелание поддерживать контакты с другими подростками в школе и вне ее. Следствием становится несформированность навыков межличностной коммуникации и проблемы построения адекватных социальных отношений в детских коллективах, о чем пишут в своих работах А.И. Лучинкина, И.С. Лучинкина, А.А. Гребенюк, Л.В. Жихарева, Т.В. Юдее- ва, и многие другие [5, 7]. Ко всему прочему виртуальная среда, освобождая подростка от нормативных рамок, ограничивающих поведение в реальной коммуникации, искажает механизмы социальной рефлексии, способствуя формированию дезадаптивных форм поведения. А несформированность нормативных представлений, как показали в своих исследованиях М.Н. Расходчикова, А.В. Сидоренков, Д.В. Сипягин, С.И. Хаирова, тесно связана с низким статусом в системе межличностных отношений в классном коллективе [6, 10, 11$]$.

Теоретический анализ научной литературы дал возможность выстроить модель структурных компонентов межличностного взаимодействия подростков, определяющих его эффективность. В качестве основных компонентов здесь выступают:

- представление о себе: самооценка, цели, ценности, представление о себе как о личности, о своих возможностях и своих желаниях;

- представления о других: кто они, что значат для подростка, чего ждут от него, и т.д.;

- представления о нормах: что можно и что нельзя допускать в отношениях, допустимые и недопустимые способы достижения цели;

- представления о ресурсах для достижения целей.

Уровень сформированности данных компонентов обеспечивает подростку эффективность построения межличностных отношений и определяет его статус в группе сверстников.

Эмпирическая проверка выдвинутых предположений осуществлялась с помощью комплекса методик, включающих социометрические и референтометрические процедуры, тестирование, анкетирование, индивидуальные и групповые интервью. Выборку исследования составили ученики 6-7 классов в возрасте 12-14 лет (64 человека) одной из Симферопольских школ.

На начальном этапе, с помощью процедуры социометрической экспертизы были определены группы подростков с разным уровнем интегрированности в групповую иерархию класса, условно названные «звезды», «принимаемые», «отвергаемые». Все дальнейшее исследование осуществлялось в сравнительном ключе между этими тремя группами.

Анализ коммуникативных и организаторских способностей испытуемых с различным социометрическим статусом, выполненный с помощью методики «КОС» В.В. Синявского, В.А. Федоришина, показал, что у подростков из группы звезд данные способности выражены на более высоком уровне, чем у представителей двух других групп: средний балл составлял 0,75 коммуникативные и 0,73 организаторские способности. У «предпо- 
читаемых» показатели коммуникативных способностей составляли 0,66 и 0,59 соответственно и на самом низком уровне данные способности были выражены у испытуемых группы «отвергаемые» - 0,47 и 0,38 баллов.

Высокий уровень коммуникативных способностей у так называемых звезд выражается в непринужденности установления контактов, четкой формулировке целей и задач взаимодействия, легкости управления процессом коммуникации. Сочетание высокого уровня коммуникативных навыков с организаторскими способностями свидетельствует об успешном использовании коммуникации как ресурса влияния на других. У подростков группы принимаемых высокий уровень коммуникативных навыков свидетельствует о выраженных способностях понимать собеседника, вступать в сотрудничество и поддерживать процесс коммуникации. Более низкий, чем у «звезд» уровень организаторских способностей может отражать менее выраженную инициативу в управлении отношениями и меньший ресурс влияния на других. Данное сочетание качеств свидетельствует скорее о направленности на адаптацию в существующей системе отношений и ее поддержание в том виде, как она сконструирована лидерами. Показатели коммуникативных и организаторских навыков у подростков группы «отвергаемые» свидетельствуют о том, что в этой группе выше доля ребят, которые испытывают затруднения, вступая в коммуникацию с другими. Им сложнее проявлять инициативу в управлении отношениями, труднее отстаивать свои интересы и разрешать конфликтные ситуации в духе переговоров. Слабо выраженные навыки самоорганизации свидетельствуют о несформированном умении подчинять свое поведение нормам и задачам межличностного взаимодействия (или школьной дисциплины).
Как развитие этих навыков отражается на психологическом самочувствии и групповом статусе подростков показано ниже.

Выраженность показателя самооценки в разных социометрических группах исследовалась с помощью тест-опросника «Определение уровня самооценки» С.В. Ковалева. Чем меньше здесь полученные значения, тем выше уровень самооценки. Наиболее высокая самооценка отмечается у представителей группы звезд (средний показатель - 23 балла), наиболее низкий уровень самооценки фиксируется в группе отвергаемых - 63 балла.

Методика Л.М. Фридман «Наши отношения» позволяет оценить не только атмосферу в классе, но отразить эмоциональное восприятие этих отношений каждым учеником в отдельности, а также обобщенное восприятие этой атмосферы представителями социометрических групп (рис1).

Как видно из графика на рисунке 1 представители группы предпочитаемых дают позитивные оценки атмосфере класса, но в сравнении с оценками представителей группы звезд, их можно назвать более умеренными. «Звезды» также высоко оценивают дружность класса, но в сравнении с «предпочитаемыми» они ее как бы переоценивают. В оценках, отвергаемых чаще представлены такие характеристики как класс не дружный, конфликтный и разобщенный. Очевидно, что эти оценки отражают положение самих «отвергаемых».

Точно также по-разному характеризуют представители социометрических групп готовность одноклассников оказывать помощь друг другу (рис. 2).

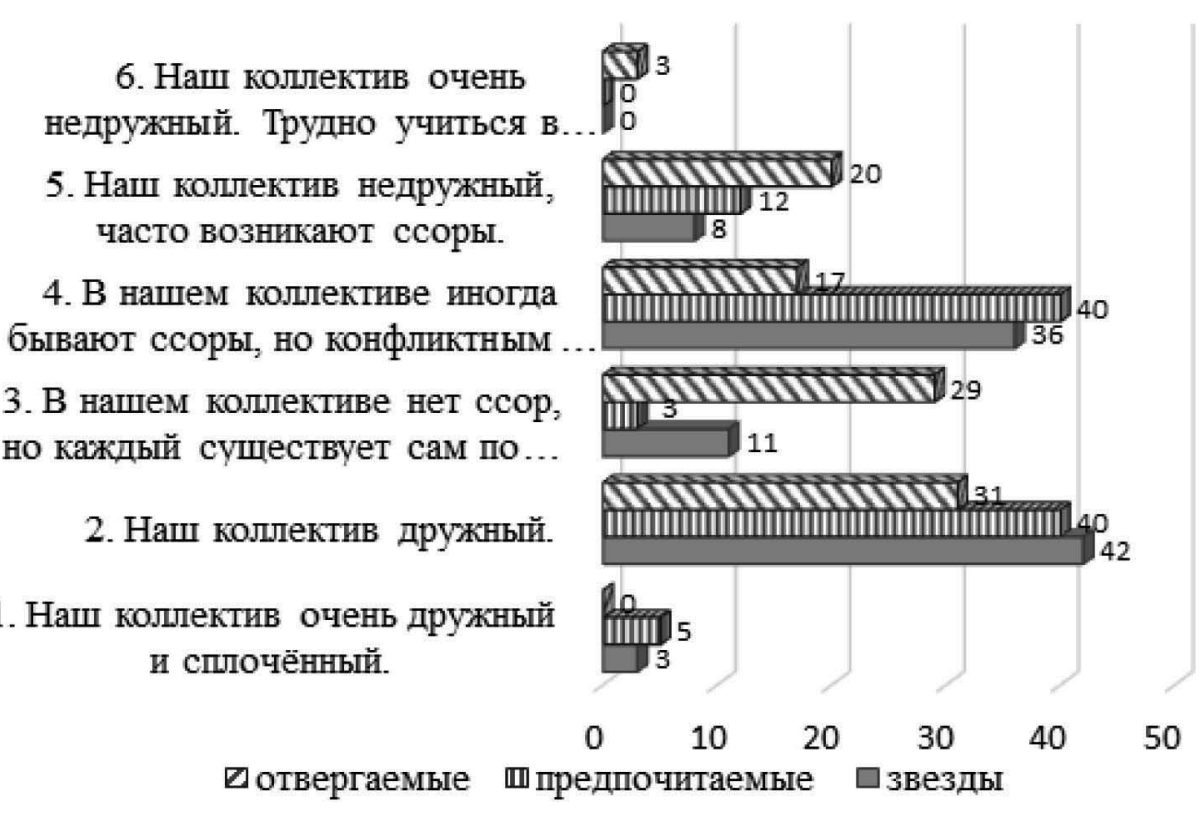

Рис.1. Оценка атмосферы в классе представителями разных социометрических групп 
6. В нашей группе отказываются помогать друг другу.

5. В нашей группе не принято помогать друг другу

4. В нашей группе помощь оказывается только тогда, когда требует учитель.

3. В нашей группе помогают только тогда, копда об этом просит сам ученик.

2. В нашей грушпе помошь оказывается только своим друзьям.

1. В нашей группе принято помогать без напоминания.

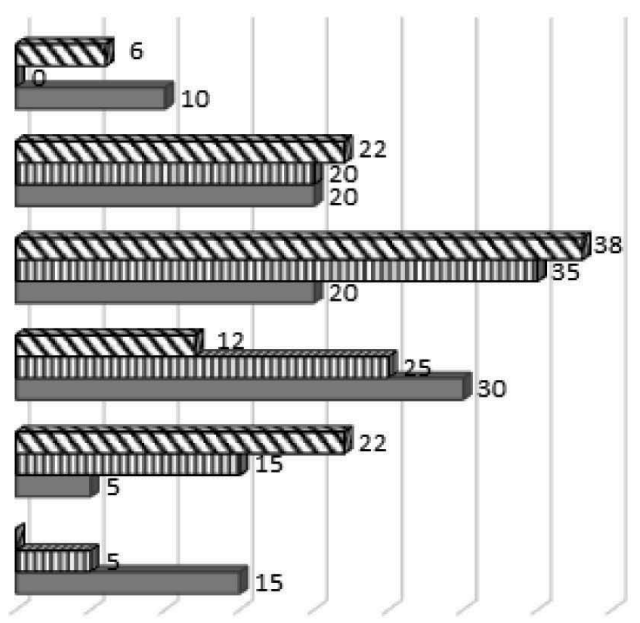

$\begin{array}{lllllllll}0 & 5 & 10 & 15 & 20 & 25 & 30 & 35 & 40\end{array}$

\section{Ø отвергаемые Ш предпочитаемые $\square$ звезды}

Рис. 2. Отношение к взаимопомощи в классе представителей разных социометрических групп.

Как поступили бы, если бы вас
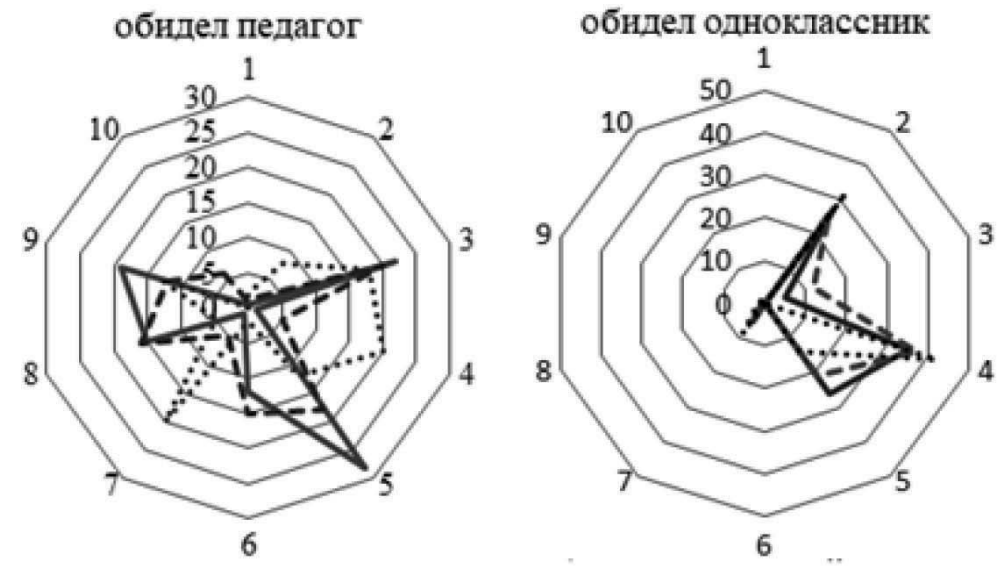

обндел однн нз роднтелей

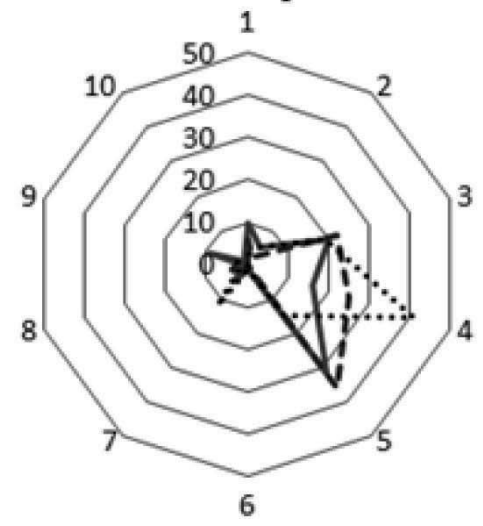

обндет посторонннй четовек

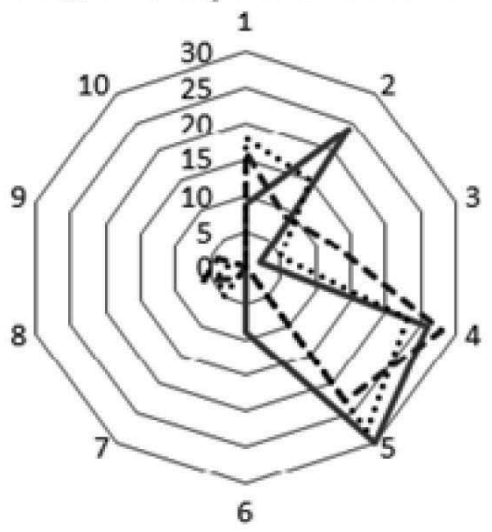

Варианты ответов:

1. промолчу;

6. пожалуюсь администрации школы;

2. отвечу дерзостью;

3. обращусь к родителям за поддержкой;

4. обращусь к товарищам за поддержкой;

5. спокойно попытаюсь доказать свою правоту;

7. при случае отомщу;

8. обращусь к классному руководителю;

9. обращусь к педагогу, которому доверяю;

10. попрошу поставить мой вопрос на классном собрании

Рис. 3. Реакция представителей социометрических групп на конфликт в различных ситуациях 
Умеренными можно назвать оценки «предпочитаемых», здесь распределение показателей ближе к нормальному. Среди звезд больше тех, кто считает, что оказывать помощь необходимо только тогда, когда одноклассник сам об этом просит, еще какая-то часть утверждает, что они помогают без напоминаний и просьб учителя. Однако «отвергаемые» видят ситуацию иначе. В их оценках преобладают такие характеристики как «помощь оказывается только по приказу учителя», «помощь оказывается только своим друзьям».

Очевидно, что подростки тяжело переживают изоляцию и самое главное - не могут изменить ситуацию самостоятельно. Кто же из взрослых пользуется у подростков доверием и может повлиять на ситуацию? Подросткам был представлен список лиц и предложено выбрать из них тех, с кем они могли бы быть откровенны: с ребятами из нашей компании; директором учебного заведения; товарищами по классу; с родителями; руководителем кружка, секции; с бабушкой или дедушкой; классным руководителем; старым знакомым; любым человеком; ни с кем. Анализ показал, что «звезды» и «предпочитаемые» в качестве доверенных лиц выбирают родителей (43\% и 38\%), друзей из своего круга (21\% и 13\%), руководителя спортивной секции (12\% и 16\%). Классного руководителя в качестве доверенного лица выбрали лишь 7\% «звезд». Существенно отличается круг доверенных людей у «отвергаемых». Их авторитеты лежат за пределами класса, основную долю которых составляют ребята из своей компании (33\%), старые знакомые (26\%), руководители спортивного кружка (13\%), бабушка или дедушка (11\%). Практически не попали в список доверенных лиц родители и школьные учителя. На наш взгляд это является серьезным индикатором неблагополучных отношений представителей данной группы не только с одноклассниками, но и окружающими взрослыми. Тут встает вопрос - что первично: подросток попал в группу отвергаемых из-за того, что у него не сложились отношения с учителем, или отношения не складываются потому, что личностные особенности подростка не позволяют выстроить нормальную коммуникацию с педагогом? Безусловно, эти два явления тесно связаны, однако понимание что первично, позволяет точно сфокусировать направление усилий, чтобы разорвать этот порочный круг.

На последующих графиках показано, как реагируют подростки на проблемы, возникающие в различных ситуациях общения (рис. 3).

Реакция на несправедливую обиду со стороны учителя. Представители группы звезд и предпочитаемых, решая проблемы взаимоотношений с учителем, чаще всего прибегают к помощи родителей, администрации или стараются разобраться сами, опираясь на собственные силы. Иначе построена стратегия поведения «отвергаемых». Здесь доминируют поиск поддержки у товарищей, либо декларация готовности свести счеты с преподавателем. В меньшей мере такие подростки склонны обращаться за помощью к авторитетному взрослому (родителю или педагогу) и в еще меньшей мере верят, что смогут решить проблему самостоятельно.

В ситуации конфликта с родителями в группах звезд и предпочитаемых преобладающей является стратегия самостоятельного разрешения ситуации. В случае, если самостоятельно решить проблему не удается, подростки стремятся прибегать к помощи товарищей или другого родителя. «Отвергаемые» реже опираются на свои силы и больше рассчитывают на поддержку друзей. Вероятно, это является отражением того факта, что у подростков этой категории изначально сложные отношения с родителями, поэтому попытка решить проблему в диалоге с ними изначально выглядит как безнадежная. В беседах с подростками обсуждался вопрос в чем именно заключается поддержка друзей. Спектр ответов варьировал от «найти эмоциональную поддержку», до «уйти из дома».

В конфликтах со сверстниками референтными лицами являются одноклассники, к поддержке взрослых подростки апеллируют значительно реже. «Звезды» и «предпочитаемые» наравне с «отвергаемыми» позволяют себе агрессию, которую сдерживают в отношениях с взрослыми. Лишь незначительная часть представителей группы предпочитаемых в случае возникновения трудностей в решении конфликта со сверстником выражают готовность обратиться за поддержкой к родителям, а представители звезд - к администрации школы. В отношениях с посторонними взрослыми все подростки ведут себя примерно сходным образом, с той лишь разницей, что «звезды» решительнее противостоят давлению взрослых, нежели представители двух других групп.

Нормативное поведение - это поведение, направленное на реализацию потребностей и целей и организованное в соответствии с установленными в обществе ценностями и образцами поведения. Исследование нормативных представлений подростков осуществлялось с помощью модифицированной методики Must-тест П.Н. Иванова и Е.Ф. Колобовой, в которую были добавлены два пункта - «тебя будут уважать, если ты...» и «тебя никто не будет уважать, если ты...». Было установлено, что наиболее значимым условием социального принятия подростки называют разделение групповых ценностей (72\% выборов), проявление собственного достоинства (67\%), взаимную поддержку и проявление социально одобряемых качеств (54\%). Обращает на себя внимание тот факт, что общение с социально отвергаемыми членами своего окружения расценивается как фактор, который может пошатнуть собственные позиции в со- 
циальной иерархии группы. Это свидетельствует о конформизме подростков и значительной подверженности социальному давлению.

Исследование выраженности нормативного поведения представителей различных социометрических групп осуществлялось с помощью шкалы «G» Многофакторного личностного опросника Р.Б. Кеттелла. Умеренную нормативность поведения продемонстрировали «звезды». Здесь примерно в равных долях представлены те, кто ориентирован на поддержание норм (52 \%) и те, у кого уровень нормативности фиксируется как низкий (48 \%). Высокую нормативность поведения продемонстрировали представители группы предпочитаемых: 76\% выборки показывают высокий уровень нормативности и 24\% низкий. В группе отвергаемых наиболее низкий уровень нормативности поведения: здесь 13\% тех, кто ориентирован на поддержание норм и $87 \%$ тех, кто показывает низкий уровень нормативности поведения. Полученные данные можно объяснить с позиции отношения представителей разных социометрических групп к нормам. Звезды сами устанавливают групповые нормы, меньше от них зависят и соответственно демонстрируют умеренное отношение к ним. Отвергаемые находятся вне структуры групповых связей, соответственно они не разделяют групповых норм. Возможно, это является ответной реакцией представителей данной группы на ту социальную изоляцию, в которой они оказались. И лишь представители предпочитаемых являются той частью классного коллектива, которая в большинстве своем поддерживает стабильность и престиж групповых норм.

Анализ полученных материалов позволяет сделать следующие выводы.

Причинами социальной успешности подростков являются не только сформированные коммуникативные и организаторские навыки, а также высокий уровень самооценки, обусловленный положительным опытом построения межличностных взаимоотношений в пространстве класса. Наиболее сформированными подобные навыки можно назвать у представителей группы звезд. Они более автономны, социально ориентированы, умеют и хотят использовать поддержку окружающих - взрослых и сверстников.

Отношение подростков к групповым нормам условно можно определить как «законодательное», «законопослушное» и «оппозиционное». Оно отражает меру влияния подростков на отношения в классе, на свое положение и на поведение других. В данной ситуации отрицание групповых норм изолированными членами классной группы видится как способ защиты своего «Я» от группового давления.
Обобщая рефлексивное восприятие атмосферы в классе, можно отметить, что подростки не просто поразному себя в ней чувствуют, но по-разному ее рефлексируют. Подростки из группы звезд склонны переоценивать ее благополучие, завышать свой уровень готовности к взаимопомощи и общей сплоченности. Тогда как отвергаемые характеризуют атмосферу в классе как разобщенную, с низким уровнем взаимопомощи, корпоративностью групповых интересов и значимостью межличностных отношений для получения психологической и иных видов поддержки.

Анализ стратегий поведения в различных типах конфликтных ситуаций показывает, что подростки, называемые звездами, в решении проблем опираются в большей мере на собственные силы и на помощь авторитетных взрослых (то есть, они умеют искать и получать эту помощь).

За пределами знакомого (безопасного) пространства отношений - родителей и педагогов, - в отношениях с незнакомыми взрослыми людьми более уверено ведут себя подростки группы звезд. Вероятно, это объясняется тем, что подростки этой группы в большей мере психологически подготовлены к построению социальных отношений вне школы, более информированы, уверены в себе. В то время как у представителей двух других групп еще значительно выражена опора на близких взрослых и друзей.

Подытоживая сказанное можно сделать вывод, что причинами социальной успешности лидеров класса, именуемых звездами, являются не столько сформированные коммуникативные и организаторские навыки, сколько позитивный опыт построения межличностных взаимоотношений: как с ровесниками, так и взрослыми. Они уверены, решительны, социально более подготовлены. Труднее всего приходится подросткам группы отвергаемых: низкий уровень самооценки, слабый ресурс влияния на отношения и собственное положение в социальной иерархии класса ставит их в условия изоляции. Очевидно, что изменить ситуацию самим, без помощи взрослых им не под силу.

Можно с уверенностью утверждать, что именно неблагополучные отношения со взрослыми - родителями и педагогами - зачастую способствуют тому, что у подростка стремительно растет ком проблем, мешающих нормальной социализации и интеграции в систему групповых отношений в классе. В значительной мере вера в себя, позитивная оценка своих способностей формируется из отношения взрослых - родителей и педагогов. Не зря ведь в ситуациях решения проблем именно подростки из группы отвергаемых реже всего прибегают к помощи родителей и учителей. 
Резюмируя изложенное можно сказать, что порочный круг, где неуверенность в себе порождает неудачи при построении системы отношений, а неудача подкрепляет неуверенность в себе, может быть разорван с помощью взрослых. В первую очередь необходимо сформировать позитивный опыт отношений. Этому немало способствует создание ситуации успеха: во внешкольной деятельности, школьных достижениях, спортивных победах всем том, что позволяет поднять авторитет подростка. Заблуждением является мысль, что для подростка низка значимость учительской похвалы или школьной отметки. Если она сделана грамотно, «по-взрослому», подростки ценят и добиваются ее. Однако для эффективного решения проблем дезадаптации подростка. необходима целенаправленная и методичная работа психологической службы школы.

Задачи формирования социальных и коммуникативных навыков подростков, навыков саморегуляции и самоорганизации, расширения спектра социально адаптивных моделей поведения, изменения установок относительно себя и окружающего мира могут быть решены методами социально-психологического тренинга. Отдельной задачей должна стоять оптимизация отношений подростка с окружающими его взрослыми - педагогами и родителями.

\section{ЛИТЕРАТУРА}

1. Абраменкова В.В. Подростковая субкультура как пространство самореализации // Мир психологии, - 2008. № 1. С. 175-189

2. Асмолов А.Г. Движущие силы и условия развития личности. // Психология личности. Т.2. Хрестоматия. - Самара: Издательский Дом «Бахрах, 2006.

3. Божович Л.И. Личность и ее формирование в детском возрасте. - М.: Прсвещение, 1968. - 464 с.

4. Выготский Л.С. Психология развития ребенка. - М: Изд-во. Смысл, Изд-во Эксмо, 2004. - $512 c$.

5. Жихарева, Л.В. Виртуальные группы смерти: методология исследования / Л.В. Жихарева // Научные ведомости БелГУ. Сер. Гуманитарные науки. - 2018. Т.37, №1. -С. 141-146. - Doi: 10.18413/2075-4574-2018-37-1-161-168. - Библиогр.: с. 145-146.

6. Коломинский Я.Л. Социальная психология школьного класса: Науч.-метод. пособие для педагогов и психологов. / Я.Л. Коломинский. -Минск: 000 "ФУАинформ", 2003. -312с.

7. Лучинкина А.И., Юдеева Т.В. Информационно-психологическая безопасность детей и подростков в интернет-пространстве // Лучинкина А.И., Юдеева Т.В. Ученые записки Крымского инженерно-педагогического университета. Серия: Педагогика. Психология. 2015. № 1. С. 19-24.

8. Мясищев, В.Н. Психология отношений : избранные психологические труды / В.Н. Мясищев. - Москва : Институт практической психологии; Воронеж: НПО 'МОДЭК', 1998. -368 c.

9. Сачкова М.Е. Статусные отношения в подростковых ученических группах // Вопросы психологии, 2006, №4. С. 58-63.

10. Сипягин Д.В. Влияние психосоциальной идентичности личности на статусно ролевую позицию индивида в группе. Автореф. канд. дисс. Москва. 2007.

11. Хаирова С.И. Особенности нормативного поведения подростков в школьной среде. // Ученые записки Крымского инженерно-педагогического университета. Серия: Педагогика. Психология. 2018. № 3 (13). С. 50-57.

(с) Хаирова Селиме Изетовна (Selime_khairova@mail.ru). 